Dicle Tıp Dergisi / Dicle Med J (2019) 46 (1) : 73 - 83

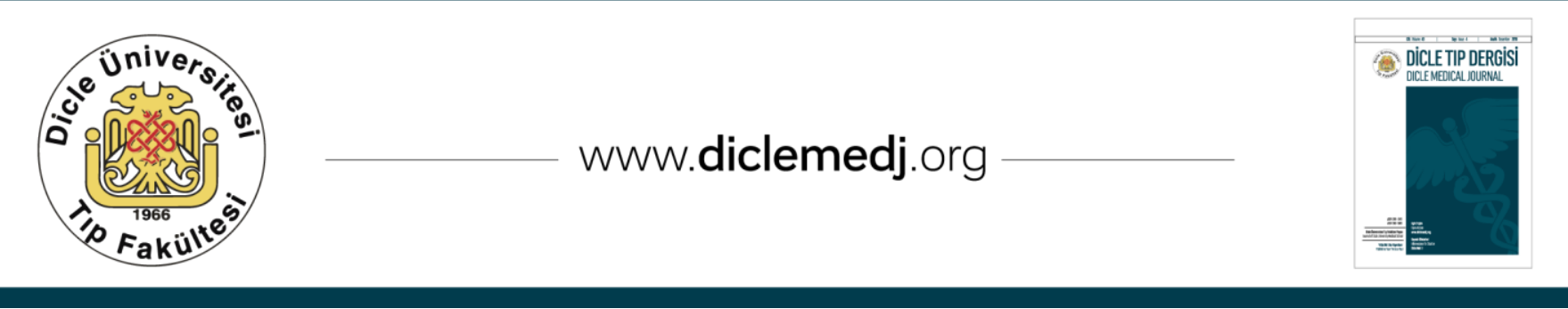

Özgün Araștırma / Original Article

\title{
İntraabdominal Apselerin Görüntüleme Eşliğinde Perkütan Drenajı
}

\author{
Çağrı Damar'1, Meltem Özdemir², Baki Hekimoğlu ${ }^{3}$ \\ 1 Gaziantep Üniv. Tıp Fakültesi, Şahinbey Araştırma ve Uygulama Hastanesi, Radyoloji Bölümü, Gaziantep, Türkiye ORCID: 0000-0001-7208-1290 \\ 2 Ankara Dıșkapı Yıldırım Beyazıt Eğitim ve Araștırma Hastanesi, Radyoloji Bölümü, Ankara, Türkiye ORCID: 0000-0002-7388-2872 \\ 3 Ankara Dışkapı Yıldırım Beyazıt Eğitim ve Araștırma Hastanesi, Radyoloji Bölümü, Ankara, Türkiye ORCıD: 0000-0002-1824-5853
}

Geliş: 16.08.2018; Revizyon: 31.01.2019; Kabul Tarihi: 05.02.2019

Öz

Giriş: Çalışmanın amacı intraabdominal apselerin perkütan drenajının fayda ve etkinliğini ortaya koymak; başarı, tekrarlama ve başarısızlık oranlarını belirlemektir.

Yöntemler: Perkütan tedavi ugulanan 50 hastadaki (26 erkek, 24 kadın; yaş aralığı: 23-88; yaş ortalaması: 53) 58 apseyle ilgili retrospektif analiz yapılmıştır. Apselerin drenajı ultrason ve floroskopi kılavuzluğunda gerçekleştirilmiştir. 12 apsede $(<5 \mathrm{~cm})$ basit iğne $(18 \mathrm{G}$, Chiba) aspirasyon metodu, geri kalan diğer 46 apsede ise Seldinger yöntemiyle perkütan kateter (6 F-14 F) drenajı uygulanmıștır.

Bulgular: Perkütan kateterizasyonların yaklaşık \%49'u (23/46) ilk haftada sonlandırılmıştır. Perkütan drenajda ilk girişimde elde edilen başarı oranı \% 63,7 (37/58)' dir. Perkütan drenajı yapılan apselerde rekürrens oranı \%19 $(11 / 58)$ bulunmuș olup bunların tümü ikincil girișimlerle tedavi elde edilmiștir. Kümülatif bașarı ve bașarısızlık oranları sırasıyla \%82,8 (48/58) ve \%5,2 (3/58) olarak belirlenmiștir. 7 apsede (\%12) temporizasyon ya da palyasyon sağlanmıştır. Temporizasyon-palyasyon sağlanan apseler ile ikincil girişimlerle tedavi edilen tüm apseler dahil edildiğinde başarı oranı \%94,8 (55/58) ve başarısızlık oranı \%5,2 (3/58) olarak belirlenmiştir. Mortalite oranı ise $\% 3,4(2 / 58)$ bulunmuştur.

Tartışma ve Sonuç: Prosedürün minimal invaziv, kolay, güvenli ve efektif oluşu, cerrahiye göre düşük komplikasyon oranları, ayrıca genel anesteziye gerek duyulmaması nedenleriyle perkütan drenaj, intraabdominal apse tedavisinde ilk seçenektir. Tedavide yüksek başarı oranları elde etmek için, güvenli giriş rotası olan tüm intraabdominal apseler görüntüleme eşliğinde perkütan drene edilmelidir.

Anahtar kelimeler: abdomen, apse, perkütan, drenaj, radyoloji

DOI: $10.5798 /$ dicletip

Yazışma Adresi / Correspondence: Çağrı Damar, Gaziantep Üniversitesi Tıp Fakültesi, Şahinbey Araştırma ve Uygulama Hastanesi, Radyoloji Bölümü, Gaziantep, Türkiye e-mail: cagridamar@hotmail.com 


\title{
Image-Guided Percutaneous Drainage of Intraabdominal Abscesses
}

\begin{abstract}
Objective: The aim of this study was to assess the effectiveness of percutaneous drainage of intraabdominal abscess, paying attention to success, recurrence and failure rates.

Methods: A retrospective evaluation of percutaneous treatment of 58 intraabdominal abscesses in 50 patients (26 male, 24 female; between the ages of 23 to 88 years old; average age: 53 years) was performed. Abscesses were drained with the guidance of sonography and fluoroscopy. 12 abscesses $(<5 \mathrm{~cm})$ drained by simple needle $(18 \mathrm{G}$, Chiba) aspiration; catheter ( $6 \mathrm{~F}$ to $14 \mathrm{~F}$ ) drainage by Seldinger technique was used in the remaining 46 abscesses.

Results: About 49\% (23/46) of percutaneous catheterizations are terminated in the first week. The success rate in the first intervention was $63.7 \%(37 / 58)$. The recurrence rate was $19 \%(11 / 58)$ and all of them treated by second attempts. Cumulative success and failure rates were $82.8 \%(48 / 58)$ and $5.2 \%(3 / 58)$, respectively. 7 abscesses $(12 \%)$ were either temporized or palliated. The overall success (with abscesses, which were temporize-palliated and required re-intervention) and failure rates were $94.8 \%(55 / 58)$ and 5.2\% (3/58), respectively. Within a one month period, the mortality rate was $3.4 \%(2 / 58)$.

Conclusions: Reasons for preference the percutaneous drainage procedure as a first choice in the treatment of intraabdominal abscess are general anesthesia avoidance, having lower complication rates than surgery and also being minimally invasive, easy, safe and effective. Image-guided percutaneous drainage should be performed in every intraabdominal abscess with a reliable access route in order to obtain high rates of therapy success.
\end{abstract}

Keywords: Abdomen, abscess, percutaneous, drainage, radiology.

\section{GİRIŞ}

İntraabdominal apse (IAA)' ler, intraperitoneal, retroperitoneal ya da visseral yerleșimli loküle pürülan sıvı koleksiyonlarıdır. Hasta kliniği değişken olmakla birlikte çoğu zaman ateş, lökositoz, artmıș eritrosit sedimentasyon hızı gibi bulgular eşlik etmektedir. Antibiyoterapinin tek başına yetersiz kaldığı ve drenaj tedavisinin uygulanmadığı durumlarda İAA'lar sepsise neden olabilmekte, \%45-100 mortal seyretmektedir. Radyolojik görüntüleme yöntemleri eşliğinde perkütan apse drenajı minimal invaziv, kolay, efektif, güvenli ve tolere edilebilir olup, cerrahiye göre düşük mortalite ve morbidite oranlarına sahiptir $^{1-4}$. Bu çalışmadaki amacımız, perkütan drenaj (PD) yöntemi uyguladığımız intraabdominal apse olgularında; kullandığımız tedavi yaklaşımı, seçilen yöntem ve araçlar ile tedaviden elde edilen sonuçların sunulmasıdır. Aynı zamanda, intraabdominal apselerin bu yöntemle tedavisinin fayda ve etkinliğinin ortaya konması, yöntemin tekrarlama ve bașarısızlık oranlarının belirlenmesi de amaçlanmıştır.

\section{YÖNTEMLER}

2007-2010 yılları arasında 50 hastada, ultrasonografi (US) ve gerekli durumlarda floroskopi kılavuzluğunda PD işlemi uygulanan 58 İAA vakasının tedavi tekniği ve takip bulguları retrospektif olarak değerlendirilmiștir. Hastaların takibi taburcu olduktan sonra poliklinik izlem süreleriyle sınırlı olmakla birlikte özellikli bazı hastaların değerlendirilmesinde, hastane arşivinden elde olunan dosya ve epikriz kayıtları ya da hastane bilgisayar otomasyon sistemiyle sağlanan veriler kaynak olarak kullanılmıştır. Bazı hastalarla ise telefonla görüşülmüştür. Hastaların yaşı 23 ile 88 arasında (ortalama 53) değişmektedir. Bunlardan 24'ü kadın, 26'sı erkek hastadır. Çalışmaya sadece enfekte olduğu kabul edilen koleksiyonlar dahil edilmiştir. Burada pürülan içerikli koleksiyonlar (kötü kokulu ve/veya kültür pozitif) ile kültür negatif koleksiyonlardan 
kliniği uygun olanlar (ateş, lokal ağrı) ya da pozitif mikroskopisi olan koleksiyonlar apse olarak değerlendirilmiştir. PD uygulanan diğer basit kist, pankreatik psödokist, asit, ürinoma, seroma, bilioma, endometrioma, lenfosel veya hematom gibi steril koleksiyonlar ile bakteriyel süperenfeksiyon gözlenmeyen kist hidatik lezyonları çalışma kapsamına dahil edilmemiştir.

Hastalarda apseye eşlik eden ko-morbid faktörler belirlenip kaydedilmiștir.

Birçok hastaya PD işleminden önce ilgili klinik hekimleri tarafından geniş spektrumlu ampirik antibiyotik tedavisi başlanmış, gram boyama ve kültür sonuçlarına göre tedaviye aynı ilaç ya da ilaç kombinasyonlarıyla devam edilmiş veya etken mikroorganizmaya etkili antibiyoterapiye geçilmiştir.

Kliniğimizde ya da hastanın tarafımıza sevkedildiği hastanelerde US ve/veya bilgisayarlı tomografi ile tespit edilmiş olan koleksiyonlar, öncelikle lokalizasyon, uygun drenaj tekniği ve güvenli drenaj yolu yönünden değerlendirilmiş ve sonrasında PD uygulanmıştır. Girișimler, Toshiba Nemio 10 (Toshiba Medical Systems, Japan) ve GE Logiq S6 (General Electric Medical Systems, USA) US cihazları eşliğinde, bunlara ait problar steril kılıf içine yerleştirilerek yapılmıștır. Floroskopik işlemler ise Siemens Angiostar (Siemens Medical Systems, Germany) dijital subtraksiyon anjiyografi cihazı kılavuzluğunda gerçekleştirilmiştir.

Hastaların tümünde işlem öncesi intravenöz yolla premedikasyon ve gerekli durumlarda intramuskular sedo-analjezi sonrası ciltte belirlenen giriş yerinin uygun saha temizliği ve örtümünü takiben lokal anestezi altında PD işlemine geçilmiştir.

İlk girişim için apse-cilt mesafesi en kısa ve en emniyetli yol seçilmiştir. Böylece major kanama, uzak duvarın perforasyonu, disseminasyon, sepsis gibi komplikasyonlar en aza indirgenmiştir. Apse poşuna, US eşliğinde 18 Gauge (G) çapında Chiba iğne ile ulaşılarak tanısal aspirasyon yapılmış, 5-10 ml pürülan sıvı Gram boyama ve kültür için ayrılmış ve çalışılmıştır. Kateterizasyon işlemi için apse poşuna iğne lümeninden 0,035 inç çapında kılavuz tel gönderilmiş, uygun çaptaki dilatörler ile drenaj yolu genişletildikten sonra kateter yerleştirilmiştir (Seldinger yöntemi).

Perkütan tedavisi yapılan toplam 58 İAA'nin 15 'i $(\% 25,8) \quad$ visseral, 20'si $\quad(\% 34,4)$ intraperitoneal, 23'ü $(\% 39,6)$ retroperitoneal yerleşimliydi.

İAA tanısı alan 50 hastanın 42'sinde (\%84) saptanan toplam 46 apse odağına (\%80) Seldinger yöntemi kullanılarak kateter drenajı uygulanmıștır. $\mathrm{Bu}$ apselerde $18(\% 38,2)$ tek lümenli kilitli pigtail (P) tipi (6-8-10 F), 29 $(\% 61,8)$ çift lümenli sump (S) tipi drenaj kateteri (12-14 F) olmak üzere toplam 47 kateter kullanılmıştır. 10 (\%20) hastadaki 5 cm'den küçük toplam 12 enfekte koleksiyona ise yanlızca perkütan iğne aspirasyon yöntemi uygulanmış, kavite içeriği tümüyle aspire edilip işleme son verilmiştir. Hastaların 5'inde (\%10) saptanan birden fazla İAA odağına ise çoklu PD işlemi uygulanmıştır.

Kateterize edilen çoğu vakada apse boşaltıldıktan ve kavite yıkandıktan sonra olası fistül ya da benzeri iştirakler açısından suda çözünen kontrast maddelerle poşogram alınmıştır.

Kateterizasyon sonrası ilgili klinik ile görüşülerek drenaj takibi ve monitörizasyonu, kateterin günde $3 \mathrm{kez} 5-10 \mathrm{ml}$ steril salin ile basınçsız irrigasyonu önerilmiştir.

Klinik (ağrı, ateş, genel durum bozukluğu vs.), laboratuvar (sedimentasyon hızı ve beyaz küre sayısının normale dönmesi vs.) ve radyolojik düzelme (kavitenin kaybolması ya da belirgin küçülmesi, drenaj miktarının 10-15 cc/gün altına düşmesi) sağlandığında kateter geri çekilmiştir. 
$\mathrm{Bu}$ çalışmada perkütan girişim sonrası cerrahi drenaja gerek duyulmaksızın klinik, laboratuvar ve radyolojik bulgularla iyileşme sağlandığı bilinen olgular için işlem başarılı kabul edilmiştir.

Primer hastalığa yönelik cerrahi girișim gerektiren ve operasyon yapılana dek hastanın genel durumunda düzelme sağlanan olgular için PD girişimleri temporizasyon kabul edilmiştir.

Sağ kalım beklentisi düşük, cerrahi yaklaşımla tedavi edilemeyecek hastalarda semptomatik ve nisbi klinik iyileşme sağlamak için uygulanan PD girişimleri palyatif kabul edilmiştir.

Septik komplikasyonlar nedeniyle ölen hastalarda ve persiste ederek cerrahi drenaj gerektiren apselerde ise PD işlemi başarısız kabul edilmiştir.

Yapılan işlemler ve hasta takip bulguları ile ilgili sayısal verilerin istatistiki analizi SPSS 22.0 programında, Ki-kare yöntemiyle hesaplanmış, $\mathrm{p}<0.05$ olasılık değerleri anlamlı kabul edilmiștir. Çalışma için Klinik Araştırmalar Etik Kurulu'ndan onay alınmıştır.

\section{BULGULAR}

Toplam 50 hastanın 34'ünde (\%68) apse oluşumu ile ilintili olabilecek operasyon ya da invaziv girişim öyküsü pozitif idi (apse etyolojisi ile ilişkilendirilemeyen operasyon ya da girişimler göz ardı edilmiştir). Geri kalan 16 (\%32) hastada tespit edilen enfekte koleksiyonlar spontan kabul edildi.

Hastalarda medikal öykü; klinik, laboratuvar ve görüntüleme bulguları yönünden apse için bir takım predispozan ve ko-morbid faktörler saptanmıştır. Bunlar arasında nefroüreterolityazis (\%16), kist hidatik (\%10), malignite (\%26), diabetes mellitus (\%26), kronik böbrek yetmezliği (\%10), Crohn hastalığı (\%4), romatoid artrit (\%2), splenektomi (\%2) gibi piyojenik enfeksiyona zemin oluşturan hastalıklar mevcut idi. Ayrıca hastaların bir kısmında kronik hepatit (\%2), tüberküloz (\%2), kronik osteomyelit (\%2) gibi bazı kronik enfeksiyonlar eşlik etmekteydi.

Kateterizasyon sürecinde Crohn hastalığı tanısı alarak primer hastalığına yönelik operasyon geçiren iki hasta için; aynı şekilde drenaj sürecinde nefrektomi yapılan bir başka hasta için PD ile temporizasyon sağlanmıştır. Sağ kalım beklentisi düşük 3 hastadaki 4 ayrı apse odağı için ise palyatif amaçlı PD işlemi uygulanmıştır.

Serviks kanseri tanısıyla opere edilen bir hastada gelişen pelvik yerleşimli apse, PD’a rağmen persiste olması sebebiyle cerrahi drenaja yönlendirilmiştir. Bu hasta ve ayrıca kateterizasyon sürecinde septik komplikasyonlar nedeniyle kaybedilen iki hasta için PD başarısız kabul edilmiştir.

PD kateteri yerleştirilen 27 hastada bulunan 28 apsede ilk kateterizasyon süresi sonunda tedavi sağlanmıştır. Sekiz hastadaki 8 apsede ise kateterizasyon sonrası ilk ay içerisinde rekürrens saptanmış, yapılan ikincil girişimler neticesinde tümü tedavi edilmiştir. İğne aspirasyonu ile tedavi edilen $5 \mathrm{~cm}$ 'den küçük 12 apsenin 3'ünde rekürrens saptanmiștır. İkincil girişim olarak bu apselerin 2'sinde iğne aspirasyonu, diğerinde kateterizasyon yapılmış ve tümünde tedavi başarılı olmuştur.

Toplam 58 apsenin 36'sinda (\%62) ilk girişimde başarı sağlanırken, rekürrens gözlenen 11'inde (\%19) ikincil girişimler neticesinde başarı elde edilmiştir.

Toplam 46 apse kavitesine yerleştirilen 47 kateterin 23'ü ( \%49) ilk haftada çekilmiş, bunların 21'inde \%91,3 toplam başarı elde edilmiştir. İlk drenajda kullanılan toplam $18 \mathrm{P}$ $(6-8-10 \quad$ F) tipi kateterden 5’i $(\% 27,8)$ kateterizasyon sürecinde tıkanıklık ve/veya efektif drenajın sağlanamaması nedeniyle daha geniş kalibrasyonlu P ya da S tipi kateterlerle değiştirilmiştir. İlk drenajda kullanılan toplam $29 \mathrm{~S}(12-14 \mathrm{~F})$ tipi kateterde ise kateterizasyon 
sürecinde değişim gerekmemiștir. İlk kateterizasyon sonrası tekrarlayan 8 apseden 5'inin yerleştirilen ilk kateteri (1 P, 4 S tipi olmak üzere) tarafımızca çekilmiş, diğer 3'ünde ise yetersiz cilt fiksasyonu gibi nedenlerle kateter erken çıkmış ya da hasta tarafından kazara çekilmiştir. Kateter değişimi ve kateterizasyon sonrası apsenin rekürrensi kateter ilintili başarısızlık kabul edildiğinde ilk girişimde kullanılan $\mathrm{P}$ ya da $\mathrm{S}$ tipi kateterlere göre elde edilen başarı oranları arasında istatistiki olarak anlamlı fark bulunmamıştır ( $p>0,05)$ (Tablo 1).

Tablo 1: Apselerde ilk girişimde kullanılan kateter çeşidi ve çapına göre başarısızlık oranları.

\begin{tabular}{|c|c|c|c|c|}
\hline & & \multicolumn{3}{|c|}{ İlk girişimde başarısızlık sayı ve oranları } \\
\hline \multicolumn{2}{|c|}{$\mathbf{p}>\mathbf{0 , 0 5}$} & Erken rekürrens & Değişim & Toplam \\
\hline \multirow{3}{*}{$\underset{(n=18)}{P}$} & $6 \mathrm{~F}$ & . & 1 & \multirow{3}{*}{$\begin{array}{c}6 \\
(\% 34)\end{array}$} \\
\hline & $8 \mathrm{~F}$ & 1 & 2 & \\
\hline & $10 \mathrm{~F}$ & . & 2 & \\
\hline \multirow{2}{*}{$\underset{(n=29)}{S}$} & $12 \mathrm{~F}$ & 4 & . & \multirow{2}{*}{$\begin{array}{c}4 \\
(\% 14)\end{array}$} \\
\hline & $14 \mathrm{~F}$ & . & & \\
\hline
\end{tabular}

İlk girişimde kullanılan P ya da S tipi kateterlerde, değişim ve kateterizasyon sonrası apsenin rekürrensi kateter ilintili başarısızlık kabul edildiğinde kateter çeşidi ve çapına göre başarısılılı oranları.

Perkütan tedavide 15 visseral apsenin 13'ünde $(\% 86,7)$ başarı, 1 apsede $(\% 6,6)$ palyasyon sağlanmış; 1 apsenin $(\% 6,6)$ tedavisinde ise başarısız olunmuştur. 20 intraperitoneal apsenin 19'unda (\%95) başarı, 1 apsede (\%5) palyasyon sağlanmıştır. 23 retroperitoneal apsenin 16'sında $(\% 69,5)$ başarı, 5'inde $(\% 21,7)$ temporizasyon ya da palyasyon sağlanmış; 2 apsede $\quad(\% 8,6)$ bașarısız olunmuştur. PD yaplan apselerin yerleşim yerlerine göre (intraperitoneal, retroperitoneal, visseral) elde edilen başarı oranları arasında; spontan ya da postoperatif gelișen apselerde elde edilen başarı oranları arasında istatistiki olarak anlamlı fark bulunmamıştır $(p>0,05)$ (Tablo 2, Tablo 3).
Tablo 2: Perkütan girişim yapılan apselerin yerleşim yerlerine göre başarılı, temporizasyon, palyasyon ve başarısızlık kategorilerinde dağılımı.

\begin{tabular}{|l|c|c|c|c|c|}
\hline \multirow{2}{*}{\multicolumn{1}{c|}{$\mathbf{p}>\mathbf{0 , 0 5}$}} & \multicolumn{2}{|c|}{ Başarılı } & \multirow{2}{*}{ T } & \multirow{2}{*}{ P } & Başarısızlık \\
\cline { 2 - 4 } & I & II & & & . \\
\hline $\begin{array}{l}\text { İntraperitoneal } \\
\text { apseler }\end{array}$ & 15 & 4 & $\cdot$ & 1 & 2 \\
\hline Retroperiton apseleri & 10 & 6 & 3 & 2 & 1 \\
\hline Visseral apseler & 11 & 2 & $\cdot$ & 1 & 3 \\
\hline TOPLAM & 36 & 12 & 3 & 4 & 3 \\
\hline
\end{tabular}

I: İlk girişimde tedavisi sağlanan apse sayısı, II: Yapılan ek girişimler ile tedavisi sağlanan apse sayısı. T: Temporizasyon sağlanan apse sayısı, P: Palyasyon sağlanan apse sayısı, Başarısızlık: Perkütan tedavide başarısız olunan apse sayısı.

Tablo 3: Kateterizasyon işleminin spontan ya da postoperatif apselerde başarılı, temporizasyon, palyasyon ve başarısızlık kategorilerinde dağılımı.

\begin{tabular}{|l|c|c|c|}
\hline \multicolumn{2}{|c|}{ P>0,05 } & SA & POA \\
\hline \multirow{2}{*}{ Başarılı } & I & 7 & 21 \\
\cline { 2 - 4 } & II & 3 & 5 \\
\hline Temporizasyon & 0 & 3 \\
\hline Palyasyon & 3 & 1 \\
\hline Başarısızlık & 2 & 1 \\
\hline \multirow{2}{*}{ TOPLAM } & 15 & 31 \\
\cline { 2 - 4 } & \multicolumn{2}{|c}{46} \\
\hline
\end{tabular}

SA: Spontan gelişen apse sayısı, POA: İlgili cerrahi operasyon ya da invaziv girişim öyküsü pozitif hastalarda gelişen apse sayısı. I: İlk girişimde tedavisi sağlanan apse sayısı, II: Yapılan ek girişimler ile tedavisi sağlanan apse sayısı.

İlk ve ikincil girişimlerle birlikte perkütan tedavi uygulanan 58 apsenin 48'inde kümülatif başarı (\%82,8), 3 apsede temporizasyon $(\% 5,2), 4$ apsede palyasyon $(\% 6,8)$ sağlanırken; 3 apsede $(\% 5,2)$ ise başarısız olunmuştur. Temporizasyon-palyasyon sağlanan apseler ile ikincil girişimlerle tedavi edilen tüm apseler dahil edildiğinde başarı oranı \%94,8 (55/58) ve başarısızlık oranı \% 5,2 (3/58) olarak belirlenmiştir. Mortalite oranı ise \%3,4 (2/58) bulunmuştur.

Kateterizasyon sürecinde; 2 hastamızda septik komplikasyonlara bağlı ölüm, 3 hastamızda transiyent bakteriyemi, sol subfrenik apseli bir hastamızda kendini sinırlayan kanama 
komplikasyonu, diğer bir hastamızda plevral efüzyon gelişmiştir.

Kültüre gönderilen apse materyallerinde, elde olunan laboratuvar sonuçları dahilinde bakteri kültürü pozitif apse sayısı 38 olup (\%65) en çok izole edilen bakteri Escherichia Coli (E. Coli) (16 apse, \%42) olmuştur.

\section{TARTIŞMA}

İAA'larda PD, \%1,4-15 gibi oldukça düşük mortalite oranlarıyla bu gün için artık yerleşmiş bir prosedürdür ${ }^{1,2}$. PD’a kıyasla pek tercih edilmeyen cerrahi drenajın mortalitesi ise \%30-43 arasında bildirilmiştir ${ }^{2}$. PD mortalitesi altta yatan birincil hastalığa, apsenin visseral lokasyonuna, mikroorganizmaların virulans ve rezistansına, hastanın immün durumuna ve sistemik hastalıklar gibi ko-morbid faktörlerin birlikteliğine bağlıdır ${ }^{2}$. $\mathrm{Bu}$ çalışmada PD sürecinde kronik sistemik hastalıkları (diabetes mellitus ve kronik böbrek yetmezliği) bulunan 2 hasta (\%4) septik komplikasyonlar nedeniyle kaybedilmiştir.

Görüntüleme eşliğinde PD başarı oranının \%70-100 arasında değiştiği bildirilmiştir ${ }^{2,3}$. Bizim serimizde PD'ın temporizasyon ve palyasyon etkinliği de dahil edildiğinde toplam başarı oranı (overall success rate) \%94,8'e ulaşmaktadır. Uygunsuz giriş yolu, düşük kalibrasyonlu kateter ile PD, kateter malpozisyonu, kırılması ya da erken çıkması, kateterin yetersiz irrigasyonu ve tıkanma, tümörün apse zannedilmesi ya da enfekte tümörler, apse içeriğinin viskozitesi ve multilokülasyon, intestinal anastomoz dehissansı, fistül varlığı, antibiyotik seçiminde hata, PD'da başarı oranının düşmesinin ve rekürrensin ana sebepleri olarak belirtilmiştir ${ }^{1,2}$. İnatçı apseler ve uzamış PD’larda kateterin daha geniş çaplı olanı ile değiştirilmesinin, bunu yaparken olası fistül varlığı açısından poşografi alınmasının faydalı olduğu gösterilmiştir 5 . Visköz apse içeriği nedeniyle yetersiz drenajı ve buna bağlı kateter değişimini önlemek adına ilk girişimde 10-14 F gibi geniş çaplı kateterlerin kullanılması tavsiye edilmektedir ${ }^{1}$. Bizim tecrübemizde de küçük çaplı (6-8-10 F) P tipi kateterlerden 5'i $(\% 27,8)$, kateterizasyon sürecinde tıkanıklık ve/veya efektif drenajın sağlanamaması nedeniyle daha geniş kalibrasyonlu olan $\mathrm{P}$ ya da $\mathrm{S}$ tipi kateterlerle değiștirilmiştir. Geniş kalibrasyonlu S tipi kateterlerde (12-14 F) ise bu tarz bir komplikasyon gelişmemiştir. Bununla birlikte bir çalışmada $7 \mathrm{~F}, \mathrm{P}$ ve $14 \mathrm{~F}, \mathrm{~S}$ tipi kateterler arasında başarı, rekürrens ya da komplikasyon oranları ve drenaj zamanları arasında anlamlı farklılık saptanmadığ bildirilmiştir ${ }^{6}$. Bizim çalışmamızda $\mathrm{P}$ ya da $\mathrm{S}$ tipi kateterler ile yapılan ilk girişimde elde edilen başarı oranları arasında istatistiki olarak anlamlı fark bulunmamıştır ( $p>0.05)$. Ancak pratikte çift lümenli yapısıyla $S$ tipi kateterlerin apse kavitesi içerisindeyken efektif vakumlanması (diğer lümenden hava giriși nedeniyle) mümkün olmamış, serbest drenaja bırakılmışlardır. $\mathrm{Bu}$ anlamda klasik $\mathrm{P}$ tipi kateterler, in- vitro yapılan bir çalışmaya paralel olarak kavitenin tümünün ilk girişim seansında vakumlanarak boşaltılmasını sağladığı için pratikte daha kullanışlı bulunmuşlardır7.

Karaciğer apselerinin PD’ında başarı oranları \%70-100 arasında değişir. Bir çalışmada 105 KC apsesinde başarı oranı \%90,5; bir diğer 96 vakalık çalışmada başarı oranı \%95 rapor edilmiştir2,8. Enfekte hidatik kist lezyonları diğer piyojenik apseler gibi tedavi edilmelidir ${ }^{1,2}$. Çalışmamızda 13 hepatik apse perkütan tedavi edilmiş olup bunlardan 5'inde radyolojik görüntüleme, drenaj ve laboratuvar verileri enfekte kist hidatik ile uyumlu bulunmuştur. $\mathrm{Bu}$ hastaların tümünde, biri palyatif olmak üzere \%100 toplam başarı oranı elde edilmiştir. Tümöral apseler, tümör rezeke edilebilir değilse drene edilebilir ${ }^{1}$. Operasyon ya da benzer girişim (endoskopik ya da perkütan) öyküsü bulunmayan bir hastanın soliter karaciğer apsesine PD uygulanmış, 
yaklaşık 6 ay sonra hasta rektosigmoid tümor tanısı ile opere olmuştur. Kolonda mukozal bariyerin bozulduğu sessiz neoplazilerde portal venöz yolla karaciğer apsesi gelişebilmekte, bu tip kriptojenik apselerde kolorektal değerlendirme yapılması önerilmektedir ${ }^{9-11}$.

Hepatik ve perihepatik apselerde biliyer iştirak tespit edilebilir; bu durum PD kararını etkilemez. Tek fark biliyer kanal bağlantılı apselerde drenaj zamanı daha fazladır. İntrahepatik biliyer sistem ilişkili ve ilişkisiz hepatik apse drenajlarında benzer kür oranları elde edilmiş, biliyer sistem iştirakli apselerde biliyer diversiyon gerekmemiștir. Ekstrahepatik biliyer sistem ilişkili apseler (özellikle enfekte biliyomalar) hepatik parankimal tamponad sağlanamadığı için, yüksek safra basıncı nedeniyle perkütan biliyer drenaj gerektirmektedir ${ }^{2}$. PD uyguladığımız hepatik apselerde biliyer iştirak saptamadık. Kolesistektomi sonrası gelişen peri-subhepatik yerleşimli geniş hacimli bir apsede (enfekte biliyoma) ise 13 günlük $P D$ tedavisi başarılı olmuştur. $\mathrm{Bu}$ hastada perkütan biliyer drenaj gerekmemiștir.

Görüntüleme eşliğinde dalak apselerinin drenajı, cerrahinin kontrendike olduğu yaşlı hastalar ile dalak dokusunun korunması arzulanan genç hastalarda splenektomiye bir alternatif olabilir ${ }^{2,12}$. Başarı oranları yaklaşık \%75 olarak bildirilmiştir ${ }^{2}$. Bu konuda veriler nispeten seyrek olup uygulanan tedavi seçenekleri değişkendir ${ }^{12}$. Bir hastamızın dalak apsesi PD ile efektif bir şekilde kateterize edilerek temporizasyon sağlansa da ileri dönemde dalakta başka bir lokalizasyonda apse ortaya çıkmış, bu süreçte ikincil girişim ya da splenektomi yapilamadan septik komplikasyonlar nedeniyle hasta kaybedilmiştir.

Subfrenik apselerin perkütan drenajında başarı oranı \%85'in üzerindedir. Özellikle solda barsaktan kaçınmak için tek yol transplevral drenaj olabilir. $\mathrm{Bu}$ yolu kullanmanın pnömotoraks, hidropnömotoraks ya da ampiyem gibi potansiyel komplikasyonları olsa da başarı oranı ekstraplevral yaklaşım ile benzerdir ${ }^{2,4}$. Bizim serimizde 12 subfrenik apseye subkostal ya da interkostal kraniale açılı rota takip edilerek PD uygulanmış ve tümünde başarı sağlanmıştır.

PD \%90 başarı oranıyla, periapendikal apselerde sepsis riskini azaltır ve temporizasyon sağlar² ${ }^{2}$ Literatürde bașarılı PD’ı takiben apendektomi gerekliliği ve zamanlaması konusunda bir takım fikir ayrılıkları mevcuttur ${ }^{12,13}$. Bu tür hastalarda ilk 6 ayda daha sık olmak üzere tekrarlayan apandisit oranları \%6-20 bildirilmiștir ${ }^{14,15}$. Çalışmamızda 2 hastanın periapendikuler apsesine başarıyla PD uygulanmıştır. $\mathrm{Bu}$ hastalardan birine perkütan tedavi sürecinden sonra elektif apendektomi yapılmış, diğeri ise opere olmamış ve 3 ylllık izlemde rekürrens ya da komplikasyon görülmemiştir.

PD, Crohn hastalığı ilişkili apseler için fistül riskini artırmaksızın efektif bir tedavi yöntemidir. PD bu hastalarda slklıkla cerrahi tedavi ihtiyacını ortadan kaldırabilir veya temporizasyon sağlayabilir ${ }^{2,13}$. Crohn hastalığını takiben ortaya çıkan matür apselerde PD ile birlikte başlangıçta kombine edilen antibiyotik, yüksek doz steroid, oral alımın kısıtlaması ve (gereklilik halinde) hiperalimentasyon, PD başarısızlık oranını düşürmektedir ${ }^{16}$. Bazı hastalarda (\%33-50), sonunda cerrahi drenaj ya da rezeksiyon gerekse de çoğu yazar hala PD’ın eğer teknik olarak mümkünse ilk aşamada denenmesini tavsiye etmektedir ${ }^{17}$. Çalışmamızda iki Crohn hastasında, teşhis ve operasyon öncesi süreçte PD ile temporizasyon sağlanmıștır.

Pelvik koleksiyonlarda drenaj; lokasyona, hasta ve hekim tercihine bağlı olarak transabdominal, transperineal, transgluteal ve endokaviter (transrektal, transvajinal) rotalar üzerinden yapılabilir $4,12,18,19$. Genel olarak olası steril koleksiyonların aspirasyon ya da drenajında en 
steril giriș rotası (transabdominal ve transgluteal rotalar) endokaviter rotalara göre tercih edilir. Transperineal yaklaşım rektum kanseri nedeniyle opere (low anterior resection) hastalarda en çok kullanılan rotadır ${ }^{12}$. Aynı öyküyle bir hastamızda bu yol kullanılarak postoperatif sağ pararektal apse başarıyla drene edilmiştir (Resim 1a, b). Literatürde endokaviter ve transgluteal rotaların karşılaştırılmasında bu prosedürler nedeniyle gelişebilen şiddetli veya persistan ağrıların seviye ve sıklığına dair bir takım fikir ayrılıkları söz konusudur. Bu rotaların tercihi durumunda sedasyon gereklidir. Transgluteal yaklaşımda persistan ağrı veya gluteal arter yaralanması gibi komplikasyonlardan kaçınmak için büyük siyatik foramende siyatik sinir mediali ve priformis kası seviyesi altından ulaşım yolu seçilmelidir 12,20,21.

Tubo-ovaryen apselerde uygun tedavi seçeneklerine ilişkin bazı tartışmalar mevcuttur. Tubo-ovaryen apsesi olan pek çok hastada antibiyotik ve destekleyici tedavi yeterli olmaktadır22. Fakat erken aspirasyon (basit koleksiyonlarda) ve drenaj (kompleks koleksiyonlarda), hastalığın uzamasının önüne geçmek ve fertilite kaybını engellemek için savunulmaktadır ${ }^{12,23}$. Sol tuboovaryen apseli bir hastamızda perkütan iğne aspirasyon ile drenaj tedavisi uygulanmış, 3 yıllık izlemde rekürrens saptanmamıştır.

PD, çoğu tüberküloz ya da pyojenik ilio-psoas apselerinde cerrahi drenaja göre efektif ve güvenli bir alternatiftir ${ }^{1}$. Bir hastamızın sol psoas apse kavitesine farklı iki noktadan 2 adet (12 ve 14 F sump) drenaj kateteri yerleştirilmiş ve kısa bir süre sonunda (3 gün) başarılı tedavi sağlanmiștır. Cantasdemir ve ark. yürüttüğü bir çalışmada 22 ilio-psoas apsesinin 17'sinde tüberküloz kültüre edilmiştir ${ }^{24}$. Bizim çalışmamızda retroperiton apseleri birlikte kategorize edilmiş, üriner sistem patolojilerine sekonder gelişen perinefritik ve ilio-psoas apselerinin pyojenik olduğu gözlenmiștir.
Kültür negatif izole ilio-psoas apseleri ise tüberküloz açısından değerlendirilmiştir.

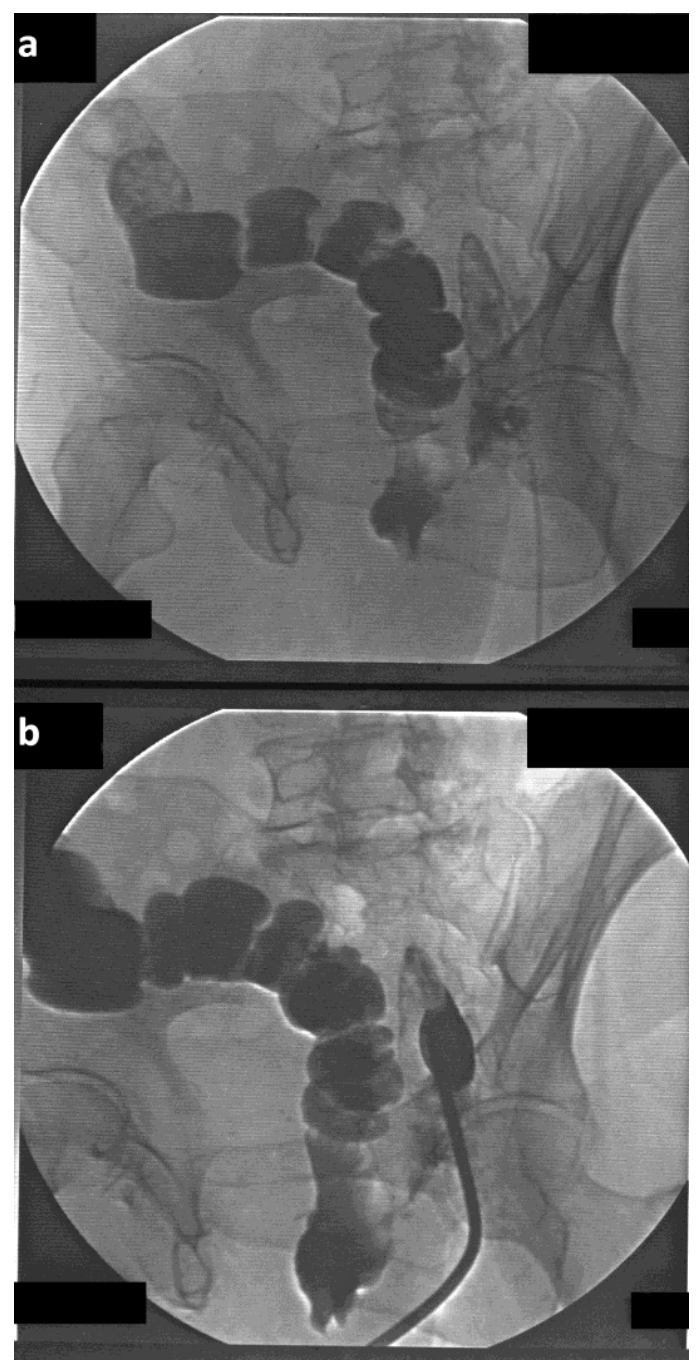

Resim 1 a, b: Kolorektal tümör nedeniyle opere hastada pararekral apsenin transperineal yaklaşımla Seldinger yöntemiyle drenajı. Kılavuz telin apse poşuna ilerletilmesi (a) ve poşa pigtail kateter yerleştirilmesi (b) aşamaları gösterilmiştir. Apse poşuna verilen kontrast maddenin bir fistül traktı ile distal kolon ansına geçişi gözlenmektedir.

Geçirilmiş laparotomi sonrası ortaya çıkan apselerde PD, antibiyoterapi ile birlikte genellikle tek gerekli tedavi metodudur. Yapılan iki çalışmada, postoperatif ve diğer apselerde elde edilen başarı oranları arasında istatistiksel olarak anlaml l fark bulunmamıştır2,12,25. Bizim çalışmamızda da benzer bir sonuç elde edilmiştir $(p>0,05)$. Postoperatif, üst abdominal ve santral 
yerleşimli apselerde uygun giriș yolu bulunamaz ise transhepatik rota ile başarılı PD yapılabileceği belirtilmiştir ${ }^{26}$.

İntestinal fistülizasyon gözlenen apselerde diğer apselere göre başarı oranı \%71-88'e gerilemektedir ${ }^{2}$. Crohn hastamızda apse kavitesi ile çekum fistülizasyonu tespit edilmiş, PD ile temporizasyon sonrası hasta elektif opere edilmiştir. Rektum karsinomu nedeniyle opere olgumuzda ise sağ pararektal yerleșimli apse poşuyla rektum arasında (olasılıkla anostomoz hattında) tespit edilen fistül traktı 12 günlük başarılı $P D$ sürecini takiben apseyle birlikte iyileşmiştir. Uterin serviks kanseri tanısıyla opere edilen bir hastamızda gelişen pelvik apse, PD’a rağmen uzun süre persiste ettiğinden cerrahi drenaja yönlendirilmiş ve operasyonda apse kavitesinde nekrotik materyal saptanmıştır. Bu olguda PD başarısız olmuştur.

İAA'ların rekürrens sıklı̆̆ı başarılı ilk drenaj sonrası \%1-10 arasında değişmektedir 2. Başka bir çalışmada tekrarlayan perkütan girişimler gerektiren rekürrens oranı hasta bazında \%23 olarak bildirilmiştir ${ }^{25}$. Tekrarlayan postoperatif apselerde PD ile yeni cerrahi girişimlerin önüne geçilebilirken pankreatik apselerde cerrahi tedavi ihtiyacı daha olasıdır ${ }^{27}$. Cinat ve ark. yaptığı çalışmada ilk girişimde elde edilen kümülatif başarı oranı, hasta bazında \%70, ikinci girişimde \%82 olarak bildirilmiştir ${ }^{25}$. Bizim çalışmamızda PD uygulanan toplam 58 apsenin 11'sinde (\%19) izlem sürecinde rekürrens saptanmış ve ikincil girişimlerle tümünde başarı sağlanmıştır. İlk kateterizasyon sonrası rekürrens saptanan 8 apsenin 3'ünde kateter kaviteden erken çıkmıştır. Kateter fiksasyonu, rekürrensin önlenmesi açısından önemlidir.

Önceki çalışmalarda PD sonrası oluşan genel komplikasyonların oranı $\% 10$ olarak bildirilmiştir ${ }^{2}$. Prosedür öncesi iyi planlama, potansiyel komplikasyonlardan kaçınmada en önemli basamaktır. Multiloküle apse vakalarında daha yüksek komplikasyon oranları söz konusudur ${ }^{2}$. Transiyent bakteriyemi PD işlemi ve/veya kateter irrigasyonu sirasinda meydana gelebilir. Girişim öncesi antibiyotik profilaksisi; kavite duvarının perforasyonundan, barsağa ve vasküler yapılara zarar vermekten kaçınmak bakteriyemi riskini azaltacaktır. Küçük boyutlu apselerin iğne aspirasyonlarında bakteriyemi riski daha düşüktür. Vasküler ve plevral komplikasyonlardan korunmak için koleksiyonun sinırları uygun görüntüleme metoduyla belirlenmelidir ${ }^{2,4,28,29}$. PD işleminde üç hastamızda transiyent bakteriyemi, sol subfrenik apseli bir hastamızda kendini sınırlayan kanama, diğer bir hastamızda plevral efüzyon gelişmiştir.

Yapılan bir çalışmada perkütan yolla alınan apse örneklerinden, kültürde en çok izole edilen iki bakteri E. Coli (fakultatif anaerob) ve Bacteroides türleri (anaerob) olmuştur ${ }^{25}$. Pyojenik KC apseleri ile ilgili güncel başka bir çalışmada yine E. Coli' nin etken mikroorganizmalar arasında başat rol oynadığını görüyoruz ${ }^{30}$. Bizim çalışmamızda da en çok izole edilen bakteri, E. Coli'dir; anaerob türlerinin izolasyonu rapor edilmemiștir. Bunun nedeni efektif anaerobik antibiyoterapiye bağlı olabileceği gibi teknik olarak uygun anaerob şartlarda kültür yapılamamasından da kaynaklanabilir.

Apse drenajı yapılacak hastalar için işlemin etkinliğini önceden belirlemeye yönelik tavsiye edilen herhangi bir laboratuvar ve klinik skorlama olmayışı çalışmanın eksik yanlarındandır ${ }^{31}$. Girișim öncesi antibiyoterapi almış, steril kültür sonucu olan vakalarda PD kür oranının diğer vakalara kıyasla daha yüksek olduğu saptanmıştır ${ }^{32}$. Bizim çalışmamızda çoğu vakada PD öncesi, geniş spektrumlu antibiyoterapi başlanmış olsa da bunun kaydı tutulmamış, diğer vakalarla kıyası yapılamamıştır. Hastaların işlem sonrası kateter bakımı ve irrigasyonunun ilgili kliniğe bırakılması, drenajın girişimsel radyoloji 
ünitesinde farklı radyoloji hekimlerince gerçekleștirilmiş olması ve buna bağlı bazı hastaların veri takibinde yaşanan aksaklıklar, iliopsoas apselerinde drenaj materyalinin ne kadarının tüberküloz açısından çalışıldığı ve bunların ne kadarının etyolojisinde tüberküloz saptandığının bilinmeyişi çalışmamızın diğer kısıtlılıkları arasındadır.

Sonuç olarak prosedürün minimal invaziv, kolay, efektif ve güvenli oluşu, tolere edilebilirliği, cerrahi tedaviye göre düşük mortalite ve morbidite oranları, ayrıca genel anesteziye gerek duyulmaması nedenleriyle PD, İAA tedavisinde ilk seçenek kabul edilmektedir. Tedavide yüksek başarı oranları elde etmek için, güvenli giriş rotası olan tüm İAA'ler radyolojik görüntüleme yöntemleri eşliğinde perkütan drene edilmelidir.

Çıkar Çatışması Beyanı: Yazarlar çıkar çatışması olmadığını bildirmişlerdir.

Finansal Destek: Bu çalışma her hangi bir fon tarafindan desteklenmemiștir.

Declaration of Conflicting Interests: The authors declare that they have no conflict of interest.

Financial Disclosure: No financial support was received.

\section{KAYNAKLAR}

1. Men S, Akhan O, Koroglu M. Percutaneous drainage of abdominal abscess. Eur J Radiol. 2002; 43: 204-18.

2. Akinci D, Akhan O, Ozmen MN, et all. Percutaneous drainage of 300 intraperitoneal abscesses with longterm follow-up. Cardiovasc Intervent Radiol. 2005; 28: 744-50.

3. Lagana D, Carrafiello G, Mangini M, et al. Image-guided percutaneous treatment of abdominal-pelvic abscesses: a 5-year experience. Radiol Med. 2008; 113: 999-1007.

4. Charles HW. Abscess drainage. Semin Intervent Radiol. 2012; 29: 325-36.

5. Gee MS, Kim JY, Gervais DA, Hahn PF, Mueller PR. Management of abdominal and pelvic abscesses that persist despite satisfactory percutaneous drainage catheter placement. AJR Am J Roentgenol. 2010; 194: 815-20.

6. Rothlin MA, Schob O, Klotz H, Candinas D, Largiader F. Percutaneous drainage of abdominal abscesses: are large-bore catheters necessary? Eur J Surg. 1998; 164: 419-24.

7. Hoyt AC, D'Agostino HB, Carrillo AJ et all. Drainage efficiency of double-lumen sump catheters and singlelumen catheters: an in vitro comparison. J Vasc Interv Radiol. 1997; 8: 267-70.

8. Haider SJ, Tarulli M, McNulty NJ, Hoffer EK. Liver Abscesses: Factors That Influence Outcome of Percutaneous Drainage. AJR Am J Roentgenol. 2017; 209: 205-13.

9. Qu K, Liu C, Wang ZX et all. Pyogenic liver abscesses associated with nonmetastatic colorectal cancers: an increasing problem in Eastern Asia. World J Gastroenterol. 2012; 18: 2948-55.

10. Koo HC, Kim YS, Kim SG et all. Should colonoscopy be performed in patients with cryptogenic liver abscess? Clin Res Hepatol Gastroenterol. 2013; 37: 86-92.

11. Lai HC, Lin CC, Cheng KS et all. Increased incidence of gastrointestinal cancers among patients with pyogenic liver abscess: a population-based cohort study. Gastroenterology. 2014; 146: 129-37.e1.

12. Lorenz JM, Al-Refaie WB, Cash BD et all. ACR appropriateness criteria radiologic management of infected fluid collections. J Am Coll Radiol. 2015; 12: 791-9.

13. Park J, Charles HW. Intra-abdominal abscess drainage: interval to surgery. Semin Intervent Radiol. 2012; 29: 311-3.

14. Hogan MJ. Appendiceal abscess drainage. Tech Vasc Interv Radiol. 2003; 6: 205-14.

15. Darwazeh G, Cunningham SC, Kowdley GC. A Systematic Review of Perforated Appendicitis and Phlegmon: Interval Appendectomy or Wait-and-See? Am Surg. 2016; 82: 11-5.

16. Poritz LS, Koltun WA. Percutaneous drainage and ileocolectomy for spontaneous intraabdominal abscess in Crohn's disease. J Gastrointest Surg. 2007; 11: 204-8.

17. Gutierrez A, Lee H, Sands BE. Outcome of surgical versus percutaneous drainage of abdominal and pelvic abscesses in Crohn's disease. Am J Gastroenterol. 2006; 101: 2283-9.

18. Harisinghani MG, Gervais DA, Hahn PF et all. CTguided transgluteal drainage of deep pelvic abscesses: indications, technique, procedure-related 
complications, and clinical outcome. Radiographics. 2002; 22: 1353-67.

19. Jaffe TA, Nelson RC, Delong DM, Paulson EK. Practice patterns in percutaneous image-guided intraabdominal abscess drainage: survey of academic and private practice centers. Radiology. 2004; 233: 750-6.

20. Harisinghani MG, Gervais DA, Maher MM et all. Transgluteal approach for percutaneous drainage of deep pelvic abscesses: 154 cases. Radiology. 2003; 228: 701-5.

21. Robert B, Chivot C, Rebibo L, et all. Percutaneous transgluteal drainage of pelvic abscesses in interventional radiology: A safe alternative to surgery. J Visc Surg. 2016; 153: 3-7.

22. Akkurt MO, Yalcin SE, Akkurt I, et all. The evaluation of risk factors for failed response to conservative treatment in tubo-ovarian abscesses. J Turk Ger Gynecol Assoc. 2015; 16: 226-30.

23. Greenstein Y, Shah AJ, Vragovic O, et all. Tuboovarian abscess. Factors associated with operative intervention after failed antibiotic therapy. J Reprod Med. 2013; 58: 101-6.

24. Cantasdemir M, Kara B, Cebi D, Selcuk ND, Numan F. Computed tomography-guided percutaneous catheter drainage of primary and secondary iliopsoas abscesses. Clin Radiol. 2003; 58: 811-5.

25. Cinat ME, Wilson SE, Din AM. Determinants for successful percutaneous image-guided drainage of intra-abdominal abscess. Arch Surg. 2002; 137: 845-9.
26. Ciftci TT, Akinci D, Akhan 0. Percutaneous transhepatic drainage of inaccessible postoperative abdominal abscesses. AJR Am J Roentgenol. 2012; 198: 477-81.

27. Gervais DA, Ho C-H, O'Neill MJ, et all. Recurrent abdominal and pelvic abscesses: incidence, results of repeated percutaneous drainage, and underlying causes in 956 drainages. American Journal of Roentgenology. 2004; 182: 463-6.

28. Venkatesan AM, Kundu S, Sacks D, et all. Practice guidelines for adult antibiotic prophylaxis during vascular and interventional radiology procedures. Written by the Standards of Practice Committee for the Society of Interventional Radiology and Endorsed by the Cardiovascular Interventional Radiological Society of Europe and Canadian Interventional Radiology Association [corrected]. J Vasc Interv Radiol. 2010; 21: 1611-30; quiz 1631.

29. Thomas J, Turner SR, Nelson RC, Paulson EK. Postprocedure sepsis in imaging-guided percutaneous hepatic abscess drainage: how often does it occur? AJR Am J Roentgenol. 2006; 186: 1419-22.

30. Serraino C, Elia C, Bracco C, et all. Characteristics and management of pyogenic liver abscess: A European experience. Medicine (Baltimore). 2018; 97: e0628.

31. Solomkin JS, Mazuski J. Intra-abdominal sepsis: newer interventional and antimicrobial therapies. Infect Dis Clin North Am. 2009; 23: 593-608.

32. Mehendiratta V, McCarty BC, Gomez L, Graviss EA, Musher DM. Computerized tomography (CT)-guided aspiration of abscesses: outcome of therapy at a tertiary care hospital. J Infect. 2007; 54: 122-8. 